\title{
Clinical and Research Activities of the Brazilian Productivity Fellows in Oral Medicine and Oral Pathology during the COVID-19 Era
}

\author{
Alison José Martelli1@, Renato Assis Machado1,2@, Daniella Reis Barbosa Martelli3 ${ }^{\circledR}$, Danyel Elias

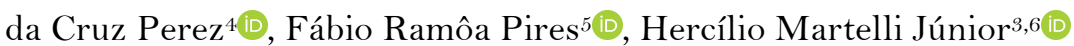

\footnotetext{
${ }^{1}$ Department of Oral Diagnosis, Dental School, University of Campinas, Piracicaba, SP, Brazil.

${ }^{2}$ Hospital for Rehabilitation of Craniofacial Anomalies, University of São Paulo, Bauru, SP, Brazil.

${ }^{3}$ Oral Diagnosis, School of Dentistry, State University of Montes Claros, Montes Claros, MG, Brazil.

${ }^{4}$ Department of Dentistry, Dental School, Federal University of Pernambuco, Recife, PE, Brazil.

${ }^{5}$ Department of Oral Pathology, School of Dentistry, State University of Rio de Janeiro, Rio de Janeiro, RJ, Brazil.

${ }_{6}^{6}$ University of Alfenas, Center for Rehabilitation of Craniofacial Anomalies, Alfenas, MG, Brazil.
}

Correspondence: Alison José Martelli, University of Campinas, 901 Limeira Avenue, Piracicaba, São Paulo, Brazil. 13414018. E-mail: alison.martelli@,gmail.com

Academic Editor: Lucianne Cople Maia

Received: 28 January 2021 / Review: 11 May 2021 / Accepted: 19 July 2021

How to cite: Martelli AJ, Machado RA, Martelli DRB, Perez DEC, Pires FR, Martelli Júnior H. Clinical and research activities of the Brazilian productivity fellows in oral medicine and oral pathology during the COVID-19 era. Pesqui Bras Odontopediatria Clín Integr. 2021; 21:e2 10018. https://doi.org/10.1590/pboci.2021.160

\begin{abstract}
Objective: To evaluate the effect of the COVID-19 impacts on the activities of researchers in the field of Oral Medicine $(\mathrm{OM})$ and Oral Pathology (OP). To assess the research activities and training of human resources by Brazilian productivity fellows in research (BPFR) in OM and OP in the COVID-19 Era. Material and Methods: Thirty-six BPFR in OM and OP areas, funded by National Council for Scientific and Technological Development $(\mathrm{CNPq})$, received a virtual structured questionnaire by e-mail, on the Google Forms $\left(\right.$ Google ${ }^{\circledR}$ ) platform, with questions regarding research activities and training of human resources (supervision of undergraduate and postgraduate students), during the COVID-19 pandemic. From the thirty-six BPFR in OM and OP, twenty-seven (75.0\%) answered the questionnaire. Results: Most of them were males $(\mathrm{n}=20 ; 74.1 \%)$ and were distributed in four Brazilian regions and ten states of the federation, including the Federal District. Twenty-four (88.9\%) BPFR reported having suspended clinical activities, while sixteen $(59.3 \%)$ answered that histopathology practices are suspended. Twenty-five (92.6\%) BPFR mentioned difficulties in conducting research projects and $55.5 \%$ stated having no difficulties in the supervision of undergraduates, master's and PhD students. Conclusion: The current scenario may significantly impact the diagnosis of oral diseases in Brazil. Moreover, a decrease in the scientific production of BPFR in OM and OP in the coming years is also considered.
\end{abstract}

Keywords: COVID-19; Oral Medicine; Pathology, Oral; Research. 


\section{Introduction}

Science can be described as a complex, self-organizing, and constantly evolving multiscale network. Scientific knowledge is composed of principles and relationships integrated into research papers, books, patents, software, and other scientific instruments, organized into scientific disciplines and wider fields [1]. Notably, scientific discoveries, new technologies, and the intensive application of cutting-edge knowledge are key factors for success in a competitive global economy [2,3].

In Brazil, there are two main science funding agencies, CAPES (Coordination for the Improvement of Higher Education Personnel, a section of the Ministry of Education) and CNPq (National Council for the Development of Science and Technology, a part of the Ministry of Science and Technology). CAPES evaluates and supports postgraduate courses and $\mathrm{CNPq}$ is the funding agency that evaluates and funds researchers based on peer assessment of the merits of the proponents and their proposals. CNPq also provides a personal form of funding for researches, called scientific productivity fellowship [4].

Numerous studies have examined the profile and the scientific productivity of Brazilian productivity fellows in research (BPFR) supported by the CNPq in several areas of knowledge [5-9] and highlighted the importance of Brazilian Oral Medicine (OM) and Oral Pathology (OP) in the international scientific scenario $[4,10]$. On February 26 (2020), approximately 56 days after the first reported case in China, Brazil officially registered the first patient with COVID-19, a 61-year-old man living in São Paulo who had recently returned from a trip to Italy [11]. Currently (May 9, 2021), Brazil surpassed 422,340 deaths and more than 13.7 million infected (https://covid.saude.gov.br).

Owing to the COVID-19 pandemic, various restrictive measures were implemented by the government, such as social distancing, closure of recreational areas, and closure of non-essential trade to reduce the contamination rate [12,13]. In Dentistry, several public and private offices had their functioning altered, as well as classes at universities, both in undergraduate and graduate levels, thereby limiting the progress of laboratory and clinical research with these restrictive measures [14,15]. Thus, in this scenario, we evaluate the research activities and training of human resources by $\mathrm{CNPq}$ BPFR in the areas of OM and OP in this COVID-19 Era.

\section{Material and Methods}

Study Design and Data Collection

This was a cross-sectional study (Research Ethics Committee \# 4.091.568). In August 2020, of the two hundred and eighteen BPFR in Dentistry (http://www.cnpq.br/web/guest/bolsistas-vigentes), thirty-six (16.5\%) described $\mathrm{OM}$ and/or OP as the main area of investigation. These thirty-six BPFR received a virtual structured questionnaire by email, on the Google Forms (Google ${ }^{\circledR}$ ) platform, with seventeen questions. The questionnaire was structured containing sociodemographic questions, besides contemplating questions related to restrictions in their clinical and laboratory activities, access to research material and activities with postgraduate students.

All CNPq BPFR in OM and OP received the link (https://forms.gle/LJNGAgDwuFkwU9A59), through personal e-mail, with information about the objectives of the study and administrative procedures. After reading and agreeing to the free and informed consent form, the participants accessed the questionnaire. The questionnaires were anonymous to ensure the confidentiality and reliability of the data. 
Data were collected and stored in a database and processed using the statistical program SPSS $^{\circledR}$ version 24.0 (Statistical Package for Social Sciences for Windows, Inc., Chicago, IL, USA), to assess the variables of interest.

\section{Results}

Of the thirty-six CNPq BPFR in OM and OP, twenty-seven (75.0\%) answered the questionnaire. The twenty-seven BPFR, predominantly males ( $\mathrm{n}=20 ; 74.1 \%)$, being $25.9 \%$ female, were distributed in four Brazilian regions and ten States of the federation and the Federal District (Table 1). As for the institution of origin, the BPFR were spread over sixteen different institutions in the country.

Table 1. Distribution of researchers in the areas of oral medicine and oral pathology according to the Brazilian regions and states.

\begin{tabular}{clc}
\hline Regions of Brazil & \multicolumn{1}{c}{ State } & $\begin{array}{c}\text { Researchers in Oral Medicine and } \\
\text { Oral Pathology } \\
\text { N }\end{array}$ \\
\hline Southeast & Minas Gerais & 5 \\
& Rio de Janeiro & 1 \\
South & São Paulo & 14 \\
Northeast & Rio Grande do Sul & 1 \\
& Bahia & 1 \\
& Ceará & 1 \\
Midwest & Paraíba & 1 \\
& Pernambuco & 1 \\
& Distrito Federal* & 1 \\
& Goiás & 27 \\
\hline *The Federal District encompasses the capital of Brazil, Brasília. & \\
& Total & 1 \\
& & \\
& &
\end{tabular}

Regarding clinical activities of dentistry, histopathology biopsy service and supervision of undergraduate, master's and $\mathrm{PhD}$ students, activities related to community services and the basis for many researches, some aspects were observed. Twenty-four (88.9\%) BPFR reported having suspended clinical activities, while sixteen (59.3\%) asserted that histopathology practices were suspended, five (18.5\%) reported performing only virtual histopathological analysis, five (18.5\%) stated both virtual and face-to-face histopathological analysis routine, and one (3.7\%) informed face-to-face histopathological analysis routine only. Fifteen (55.5\%) BPFR mentioned having no difficulties in the supervision of undergraduate, master's and PhD students, and twelve (44.4\%) reported difficulties (Table 2 ).

Twenty-five (92.6\%) BPFR mentioned difficulties in conducting research projects. These limitations included receiving materials and equipment $(74.1 \%)$, difficulties in using research facilities $(88.9 \%)$, limitations in the use of digital tools and platforms (11.1\%), data collection (88.9\%), and difficulties in communicating with other researchers $(22.2 \%)$ (Table 2$)$.

Table 2. Activities limitation of the CNPq productivity fellows in the area of oral medicine and oral pathology during the COVID-19 pandemic.

\begin{tabular}{lc}
\multicolumn{1}{c}{ Variables } & $\mathbf{N}(\%)$ \\
\hline Histopathology laboratory activities & $16(59.3)$ \\
Activities were suspended & $5(18.5)$ \\
Remotely & $5(18.5)$ \\
In person and remotely & $1(3.7)$ \\
In person &
\end{tabular}

Clinical activities 


\begin{tabular}{|c|c|}
\hline Activities were suspended & $24(88.9)$ \\
\hline Remotely & $1(3.7)$ \\
\hline In person and remotely & $1(3.7)$ \\
\hline In person & $1(3.7)$ \\
\hline \multicolumn{2}{|c|}{ Difficulty in the supervision of undergraduate or graduate students } \\
\hline Yes & $12(44.4)$ \\
\hline No & $15(55.6)$ \\
\hline \multicolumn{2}{|l|}{ Research activity limitation } \\
\hline Yes & $25(92.6)$ \\
\hline No & $2(7.4)$ \\
\hline \multicolumn{2}{|c|}{ Difficulty on receipt of research supplies or equipment } \\
\hline Yes & $20(74.1)$ \\
\hline No & $7(25.9)$ \\
\hline \multicolumn{2}{|c|}{ Difficulty of locomotion to the research location } \\
\hline Yes & $24(88.9)$ \\
\hline No & $3(11.1)$ \\
\hline \multicolumn{2}{|c|}{ Limited access to the internet or other digital tools } \\
\hline Yes & $3(11.1)$ \\
\hline No & $24(88.9)$ \\
\hline \multicolumn{2}{|c|}{ Inclusion of research using digital platforms for data collection } \\
\hline Yes & $14(51.9)$ \\
\hline No & $13(48.1)$ \\
\hline \multicolumn{2}{|c|}{ Limitations on data collection or similar } \\
\hline Yes & $3(11.1)$ \\
\hline No & $24(88.9)$ \\
\hline \multicolumn{2}{|c|}{ Difficulty communicating with research collaborators } \\
\hline Yes & $6(22.2)$ \\
\hline No & $21(77.8)$ \\
\hline
\end{tabular}

Regarding the general considerations made by the BPFR in OM and OP, some were common, such as: rethinking the use of information technologies for research and postgraduate practices, delay in completing master's and $\mathrm{PhD}$ projects, flexibility in deadlines for final research reports, motivation and concern for mental health, and a longer time for writing papers.

\section{Discussion}

Despite all the financial limitations involved in supporting Brazilian research [16,17], the BPFR contribute with publications in the main journals in $\mathrm{OM}$ and $\mathrm{OP}$, resulting in a valuable international scientific production [4,10]. According to the Advisory Committee for Dentistry of CNPq (2018-2020), the criteria for selection of scholarship include number of publications and impact factor of the journals, number of PhD theses supervised (tutored and approved), contribution to innovation, coordination and participation in research projects, leadership of research groups, participation in editorial activities, and scientific management management.

Of the 27 BPFR who participated in the study, 74.1\% were male. Analyzing the profile of the BPFR, we noticed the predominance of male gender involving other areas, such as Chemistry [7] and Medicine $[6,18]$. However, this fact has been changing in the last years, especially in Nursing and Physiotherapy, in which we observed the predominance of females among the CNPq BPFR [19,20]. Regarding the geographic distribution of BPFR, the present study pointed out a greater concentration of grants in the Southeast region $(74.1 \%)$, a fact that corroborates studies involving other areas of knowledge [6,17,23,24].

The services of $\mathrm{OM}$ and $\mathrm{OP}$ in Brazil are concentrated in public and private universities and in the unified health system, particularly in a program called the Access and Quality Improvement Program of the 
Centers of Dental Specialties (PMAQ-CEO). With the COVID-19 pandemic, all face-to-face classes were suspended in Brazil, including interruption of ongoing research activity, clinical trials and case studies [25]. Moreover, most public and private dental services were encouraged to attend only urgencies [26]. The Brazilian scenario associated with the diagnosis and treatment of oral diseases, including cancer and biopsies, is greatly impaired [27,28], with no prospect of returning to normal. In the present study, $88.9 \%$ of the BPFR reported having suspended clinical activities, while 59.3\% answered that histopathology practices were suspended. Even with this scenario, some pathology laboratory service has used digital means of work in order to circumvent restrictive measures [29].

During this quarantine period, tele(oral)medicine has been shown to be important [27,30,31]. In Brazil, there is still no legislation on dental tele(oral)service. An example of its importance is the high incidence of oral cancer in the country. The number of new cases of oral cancer expected in Brazil for each year of the 2020-2022 triennium will be 11,180 cases in men and 4,010 in women (https://www.inca.gov.br/tipos-decancer/cancer-de-boca). In recent studies, the average number of OM clinical consultations in Brazil in the prepandemic period compared with the pandemic period revealed a reduction of $65.59 \%$, changes observed even in the treatment of head and neck cancer no longer being the surgical treatment as the first choice [32, 33].

One of the most important activities of CNPq BPFR is the training of human resources. Our results showed that $44.5 \%$ of the BPFR mentioned having difficulties in supervising undergraduate, master's and PhD students. As the COVID-19 pandemic passes, there is a concern that these numbers may worsen, specially highlighting that BPFR mentioned possible involvements with mental health. This lack of psychological structure to confront the pandemic can lead to loss of motivation reflecting further on their activities [34]. In another study, we demonstrated that $\mathrm{CNPq}$ BPFR in OM and OP, throughout their career, counseled 483 undergraduate students in research (median 14.20), 326 master's students (median 9.58), and 241 PhD students (median 7.08). The median Hirsch Index of the Institute for Scientific Information (Hindex ISI) of the fellows is 15.14 .

A significant proportion of BPFR (92.6\%) reported that they are having difficulties in conducting research projects. Several factors were emphasized, such as: receipt of supplies and/or equipment, difficulties in the use of research facilities, limitations in the use of digital tools and platforms, data collection and difficulties in communicating with other researchers.

\section{Conclusion}

The COVID-19 pandemic has intensified the deep crisis of research funding in Brazil that is affecting the BPFR in OP and OM. The majority of the BPFR revealed that histopathology laboratory and clinical activities were suspended and some difficulties in performing research projects, including obtaining materials and equipment, difficulties in using research facilities, limitations in the use of digital resources and networks, data collection, and difficulties in interacting with other researchers. Considering the number of publications by the BPFR, in addition to the deficiency of human resources training due to suspended activities, together, this current scenario can result in a significant impact on the diagnosis of oral lesions and in a decrease in the scientific production of Brazilian OM and OP.

\section{Authors' Contributions}

AJM (D) https://orcid.org/0000-0002-5361-9240

Conceptualization, Methodology, Formal Analysis, Investigation, Data Curation, Writing Original Draft, Writing - Review and Editing, Visualization and Supervision. 
RAM (D) https://orcid.org/00oo-0002-1697-3662 DRBM (iD) https://orcid.org/0000-0002-7497-6052 DECP (i) https://orcid.org/0000-0002-4591-4645 FRP (iD https://orcid.org/0000-0003-0317-8878

HMJ (D) https://orcid.org/0000-0001-9691-2802 All authors declare that they contributed to critical review
Conceptualization, Methodology, Formal Analysis, Investigation, Data Curation, Writing Original Draft, Writing - Review and Editing, Visualization and Supervision.

Formal Analysis and Writing - Review and Editing.

Writing - Review and Editing.

Formal Analysis and Writing - Review and Editing.

Conceptualization, Writing - Review and Editing, Supervision and Project Administration.

of intellectual content and approval of the final version to be published.

\section{Financial Support}

This study was financed in part by the Coordenação de Aperfeiçoamento de Pessoal de Nível Superior - Brasil (CAPES) - Finance Code 001, the National Council for Scientific and Technological Development (CNPq) and the Minas Gerais State Research Foundation (FAPEMIG).

\section{Conflict of Interest}

The authors declare no conflicts of interest.

\section{Data Availability}

The data used to support the findings of this study can be made available upon request to the corresponding author.

\section{References}

[1] Fortunato S, Bergstrom CT, Bürnen K, Eyane JA, Helbing D, Milojevic S, et al. Science of science. Science 2018; 359(6379):1-21. https://doi.org/10.1126/science.aao0185

[2] Foundation NS. Research and Development: U.S. Trends and International Comparisons. Science and Engineering Indicators. Alexandria, VA, National Science Foundation. 2018.

[3] Oliveira EA, Martelli Júnior H, Simões e Silva AC, Martelli DRB, Oliveira MCL. Science funding crisis in Brazil and COVID-19: deleterious impact on scientific output. An Acad Bras Cienc 2020; 92(4):e20200700. https://doi.org/10.1590/0001-376520202020200700

[4] Andrade RS, Martelli DRB, Swerts MSO, Oliveira EA, Martelli Júnior H. Scientific production of the Brazilian Council for Scientific and Technological Development $(\mathrm{CNPq})$ researchers in the field of Oral Medicine and Oral Pathology granted with a scientific productivity fellowship. Oral Surg Oral Med Oral Pathol Oral Radiol 2018; 126(6):553-4. https://doi.org/10.1016/j.oooo.2018.07.057

[5] Barata RB, Goldraum M. A profile of researchers in public health with productivity grants from the Brazilian National Research Council (CNPq). Cad Saude Publica 2003; 19(6):1863-76. https://doi.org/10.1590/s0102-311x2003000600031

[6] Mendes PHC, Martelli DRB, Souza WPD, Quirino Filho S, Martelli Júnior H. Profile of scientific productivity scholarship researchers in medicine at CNPq, Brazil. Rev Bras Educ Med 2010; 34(4):535-41. https://doi.org/10.1590/So100-55022010000400008

[7] Santos NCF, Cândido LFDO, Kuppens CL. Research productivity of cnpq: analysis of the chemistry researchers' profile. Química Nova 2010; 33(2):489-95. https://doi.org/10.1590/So100-40422010000200044

[8] Oliveira EA, Colosimo EA, Martelli DR, Quirino IG, Oliveira MCL, Lima LS, et al. Comparison of Brazilian researchers in clinical medicine: are criteria for ranking well-adjusted?. Scientometrics 2012; 90(2):429-43. https://doi.org/10.1007/s $11192-011-0492-9$

[9] Dias GP, Martelli DRB, de Almeida LB, Barbosa GA, Oliveira EA, Martelli Júnior H. Scientific production of the Brazilian National Council for Scientific and Technological Development (CNPq) researchers in the fields of tropical medicine and infectious diseases. Rev Soc Bras Med Trop 2019; 52:e20190034.

https://doi.org/10.1590/0037-8682-0034-2019

[10] De Andrade RS, Martelli DRB, Almeida OP, Lopes MA, Swerts MSO, Pires FR, et. al. Brazilian scientific production in Oral Medicine and Oral Pathology. Oral Surg Oral Med Oral Pathol Oral Radiol 2018; 125(2):170-81. https://doi.org/10.1016/j.oooo.2017.08.009

[11] Simões E, Silva AC, Oliveira EA, Martelli HJR. Coronavirus disease pandemic is a real challenge for Brazil. Front Public Health 2020; 8:268. https://doi.org/10.3389/fpubh.2020.00268

[12] Chaudhr YR, Dranitsaris G, Mubashir T, Bartoszko J, Riazi S. A country level analysis measuring the impact of government actions, country preparedness and socioeconomic factors on COVID-19 mortality and related health outcomes. E Clin Med 2020; 25:100464. https://doi.org/10.1016/j.eclinm.2020.100464

[13] Nussbaumer-Streit B, Mary V, Dobrescu AI, Chapman A, Persad E, Klerings I, et al. Quarantine alone or in combination with other public health measures to control COVID-19: a rapid review. Cochrane Database Syst Rev 2020; 4(4):CD013574. https://doi.org/10.1002/14651858.CD013574

[14] Martelli H, Machado RA, Martelli DRB, Della Coletta R. Oral medicine, oral pathology and coronavirus (2019nCoV). Braz J Oral Sci 2020; 19:e200001. https://doi.org/10.20396/bjos.v 19io.8658890 
[15] Machado RA, De Souza NL, Oliveira RM, Martelli Júnior H, Bonan PRF. Social media and telemedicine for oral diagnosis and counselling in the COVID-19 era. Oral Oncol 2020; 105:104685. https://doi.org/10.20396/bjos.v19io.8658890

[16] Martelli Júnior H, Martelli DR, Silva ACSE, Oliveira MCL, Oliveira EA. Brazil's endangered postgraduate system. Science 2019; 363(6424):240. https://doi.org/10.1126/science.aav9015

[17] Oliveira MC, Martelli DR, Pinheiro SV, Miranda DM, Quirino IG, Leite BG, et. al. Profile and scientific production of Brazilian National Council of Technological and Scientific Development researchers in Pediatrics. Rev Paul Pediatr 2013; 31(3):278-84. https://doi.org/10.1590/S0103-05822013000300002

[18] Martelli-Júnior H, Martelli DRB, Quirino IG, Oliveira MCLA, Lima LS, Oliveira EAD. CNPq researchers in the field of medicine: comparison of the areas of activity. Rev Assoc Med Bras 2010; 56(4):478-83. https://doi.org/10.1590/S0104-42302010000400024

[19] Sturmer G, Viero CC, Silveira MN, Lukrafka JL, Plentz RD. Profile and scientific output analysis of physical therapy researchers with research productivity fellowship from the Brazilian National Council for Scientific and Technological Development. Braz J Phys Ther 2013; 17(1):41-8. https://doi.org/10.1590/S1413-35552012005000068

[20] Mombasa WDS, Padoin SMDM, Lacerda MR, Gueterres ÉC. Profile of scholarship researchers in nursing research productivity. Rev Enfer 2015; 9:844-50.

[21] Arntz M, Yahmed SB, Berlingieri F. Working from home and COVID-19: The chances and risks for gender gaps. Intereconomics 2020; 55(6):381-6. https://doi.org/10.1007/s10272-020-0938-5

[22] Malhotra A, Mather M. Do schooling and work empower women in developing countries? Gender and domestic decisions in Sri Lanka. Sociol Forum 1997; 12:599-630. https://doi.org/10.1023/A:1022126824127

[23] Sales GH, Martelli DRB, Oliveira EA, Dias VO, Oliveira MCLA, Martelli Júnior H. Evaluation on the scientific production in fields of medicine: a comparative study. Rev Bras Educ Med 2017; 41(2):290-8. https://doi.org/10.1590/1981-52712015v41n2rb20160099

[24] Wendt GW, Lisboa CSDM, De Sousa DA, Koller SH. Profile of researchers in Psychology with productivity grants from Brazil's national council of technologiocal and scientific development (CNPQ). Psicol Cienc Prof 2013; $33(3): 536$. https://doi.org/10.1590/S1414-98932013000300003

[25] De Matthews D, Knight D, Reyes P, Benedict A, Callahan R. From the field: education research during a pandemic. Educ Res 2020; 49(6):398-402. https://doi.org/10.3102/0013189X20938761

[26] Martelli-Júnior H, Machado RA, Bonan PRF, Perez DEC, Pires FR, Alves FA. Brazilian oral medicine and oral pathology: we are here during the COVID-19 pandemic. Oral Dis 2020; 27(s3):757-9. https://doi.org/10.1111/odi.13440

[27] Machado RA, Bonan PRF, Martelli PJL, Alves FA, Martelli Junior H. Brazilian oral medicine and oral histopathology services: the worrying reality in the COVID-19 Era. Oral Dis 2020; 2020. https://doi.org/10.1111/odi.13624

[28] Araújo ALD, do Amaral-Silva GK, Pérez-de-Oliveira ME, Gallagher KPD, López de Cáceres CVB, Roza ALOC, et al. Fully digital pathology laboratory routine and remote reporting of oral and maxillofacial diagnosis during the COVID-19 pandemic: a validation study. Virchows Arch 202 1; 13:1-11. https://doi.org/10.1007/s00428-02 1-03075-9

[29] Cunha AR, Antunes JLF, Martins MD, Petti S, Hugo FN. The impact of the COVID-19 pandemic on oral biopsies in the Brazilian National Health System. Oral Dis 2020; 2020. https://doi.org/10.1111/odi.13620

[30] Gueiros LA, Melo TS, Carrard VC. A simple tool to a complex reality-whatsapp use in a developing country during COVID-19 pandemic. Oral Dis 2021;27(Suppl 3):796-7. https://doi.org/10.1111/odi.13495

[31] Villa A, Sankar V, Shiboski C. Tele(oral)medicine: a new approach during the COVID-19 crisis. Oral Dis 2021; 27(Suppl 3):744-5. https://doi.org/10.1111/ odi.13364

[32] Marques NP, da Silveira DMML, Martelli PJL, Martelli DRB, de Lucena EHG, Martelli-Júnior H. Brazilian Oral Medicine and public health system: The enormous impact of the COVID-19 Era. Oral Dis 2020; 2020. https://doi.org/10.1111/odi.13677

[33] Martelli AJ, Machado RA, Pereira WM, Silveira DMM, da Cruz Perez DE, Martelli Júnior H. Impact of the COVID19 pandemic in the head and neck cancer treatment in the Brazil. Oral Oncol 2021; 116:105148. https://doi.org/10.1016/j.oraloncology.2020.105148.

[34] Pardo JC, Ramon D, Stefanelli-Silva G, Elegbede I, Lima LS, Principe SC. Advancing through the pandemic from the perspective of marine graduate researchers: challenges, solutions, and opportunities. Front Mar Sci 2020; 7:528. https://doi.org/10.3389/fmars.2020.00528 